\title{
The effect of Minimum Quantity Lubrication on the the FSW Process Performance
}

\author{
Wisam Al-Wajidi \\ School of Engineering \\ University of Guelph \\ Guelph, Ontario, Canada \\ walwajid@uoguelph.ca
}

\author{
Ibrahim Deiab \\ School of Engineering \\ University of Guelph \\ Guelph, Ontario, Canada \\ ideiab@uoguelph.ca
}

\author{
Fantahun M. Defersha \\ School of Engineering \\ University of Guelph \\ Guelph, Ontario, Canada \\ fdefersh@uoguelph.ca
}

\begin{abstract}
The effect of Minimum Quantity Lubrication (MQL) on performance of Friction Stir Welding (FSW) process for Aluminum Alloy 6061-T651 plates was investigated. MQL was used as a cooling and lubrication medium. Five different levels of rotational speed and three feed speed ranges with and without MQL were tested. The effect of MQL on the mechanical properties of the weld joints was studied throughout means of Ultimate Tensile Strength (UTS) tests. Statistical analyses were run to study the relationship between certain process parameters and response. The results showed that the average UTS of the welds is improved when MQL was applied to most of the process variables. The highest UTS was achieved at spindle speed with $1600 \mathrm{rpm}$ and with feed rate $180 \mathrm{~mm} / \mathrm{min}$ due to improvement of the grain growth.
\end{abstract}

Keywords-component; FSW; friction stir welding; MQL; Aluminum Alloys; AA6061-T651; statistical analysis

\section{INTRODUCTION}

Over the past decade, manufacturing companies have been forced to consider the environmental and social effects of their products instead of only focusing on economic benefits. Sustainability implies dealing with more than simply analyzing and modifying the performance of manufacturing processes as related to the environment. Aluminum is promising for the automotive industry because of its high strength/weight ratio, emissions, safety, corrosion resistance, and sustainability [1]. Unfortunately, high thermal and electrical conductivity of aluminum alloys are problematic in fusion and resistance welding [2]. The researchers have investigated relevant aspects, such as FSW method mechanics, metallurgical evolution of the material, the material flow, and bonding conditions. They have focused on finding effective welding variables for various materials to optimize the performance of the joints [3].

The friction stir welding process (FSW) avoids the usual problems that occur when using conventional welding to join low melting point materials or dissimilar materials. In FSW, metals are welded without attaining the melting temperature of the metals. During the FSW processes, the rotating probe slowly moves into a butt joint line between two rigidly clamped plates or sheet metals as shown in Figure 1.

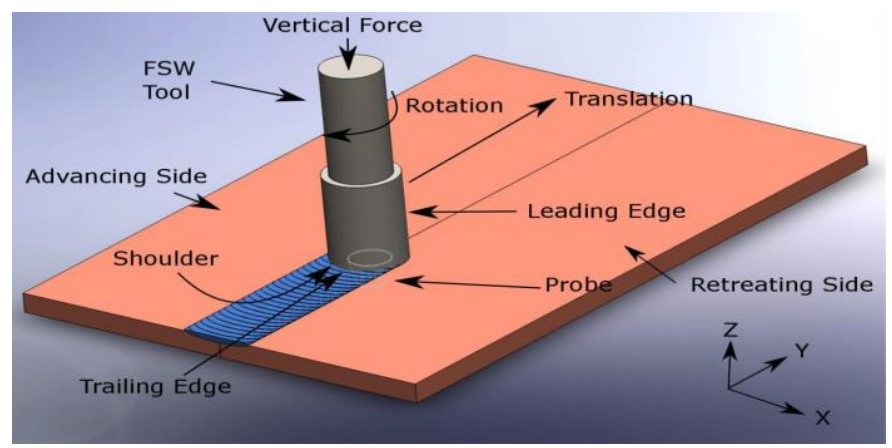

FIGURE. 1: SCHEMATIC ILLUSTRATION OF FRICTION STIR WELDING

FSW processes were first applied on aluminum alloys because of their low melting temperatures, and were found to be an effective technique. Improvement of the strength of common friction stir welded joints is possible through careful control of temperature. In several solid-state welding techniques, external liquid cooling has been used to improve weld performance. Frictional contact between the workpiece and the tool shoulder, while the tool is traveling, will generate heat; usually, the temperature is about 80 to $90 \%$ of the melting temperature of the materials [4]. 
There are several parameters in FSW that can be employed to control the process. These include spindle speed, feed speed, tool geometry, and tilting angle of the tool. Cooling strategies are one of several possible techniques to enhance the properties of the friction stir welding process. Several studies have investigated the effect of cooling strategies on the properties of friction stirring tools and the FSW joints.

As a new and sustainable method of lubrication and cooling, MQL optimizes the use of metalworking fluids [5]. The MQL process replaces regular lubrication methods, resulting in more sustainable manufacturing processes, thus acting as an achievement-oriented technology. This process has been widely verified as a near-dry process with respect to human health, cost, and environmental friendliness. The MQL process uses a small quantity of oil and sprays of compressed air. As a cooling system it is used for many manufacturing processes, but has not previously been used for FSW. Because MQL uses small amounts of highly biodegradable and environmentally friendly oils, it has promise as a sustainable manufacturing process.

The main objective of this research is to study the effect of the MQL scheme on the FSW process and the joints of AA 6061-T651 within appropriate process parameters.

\section{METHODOLOGY}

\section{A. Experimental Design}

The present study uses a full factorial experimental design (FFD) to achieve the response measurements. A statistical analysis of variance (ANOVA) test is conducted to determine the corresponding importance value of the input variables. Straightforwardly, the objective of the ANOVA test in this study is to distinguish which process variables are significant, and to determine the contribution of each variable. To compare pairs of treatment means and to find which process variable has a significant effect, the Fisher Least Significant Difference (LSD) method is used with $95 \%$ confidence. For analyzing the results, Minitab software was utilized to investigate the statistical analysis. Five different levels of rotational speed and three feed speed ranges are applied in this study, in addition to the coolant lubrication strategies in two levels as shown in Table (1).

TABLE I. : FSW PROCESS CONDITIONS

\begin{tabular}{|c|c|c|c|c|c|}
\hline Spindle Speed (rpm): & 1000 & 1300 & 1600 & 1900 & 2200 \\
\hline Feed rate $(\mathrm{mm} / \mathrm{min})$ : & 100 & 180 & 260 & & \\
\hline
\end{tabular}

\section{B. Experimental Setup}

The FSW processes in this study will use $3.175 \mathrm{~mm}$ plate sample thickness of AA 6061-T651 cut into $65.5 \times 56.5 \mathrm{~mm}$ workpieces. Table 2 shows the typical mechanical properties of AA 6061-T651.
TABle 2: The MechaniCAL PROPERTIES OF AA 6061-T6 [6]

\begin{tabular}{|c|c|c|c|}
\hline $\begin{array}{c}\text { Ultimate Tensile } \\
\text { strength }(\mathbf{M P a})\end{array}$ & $\begin{array}{c}\text { Tensile strength } \\
(\mathbf{M P a})\end{array}$ & $\begin{array}{c}\text { Yield strength } \\
(\mathbf{M P a})\end{array}$ & $\begin{array}{c}\text { Elongation } \\
(\boldsymbol{\%})\end{array}$ \\
\hline $260-310$ & $228-283$ & $193-262$ & $10-11.62$ \\
\hline
\end{tabular}

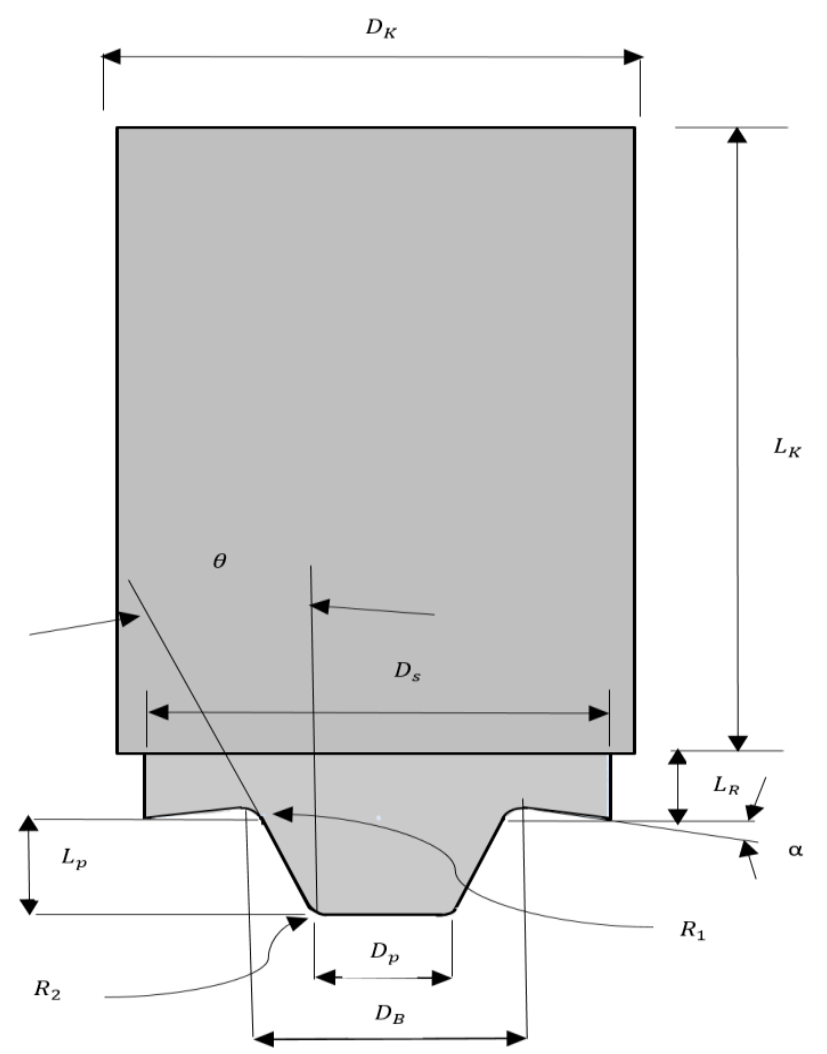

FIGURE (2) DEMONSTRATES THE GEOMETRICAL DIMENSIONS OF THIS TOOL.

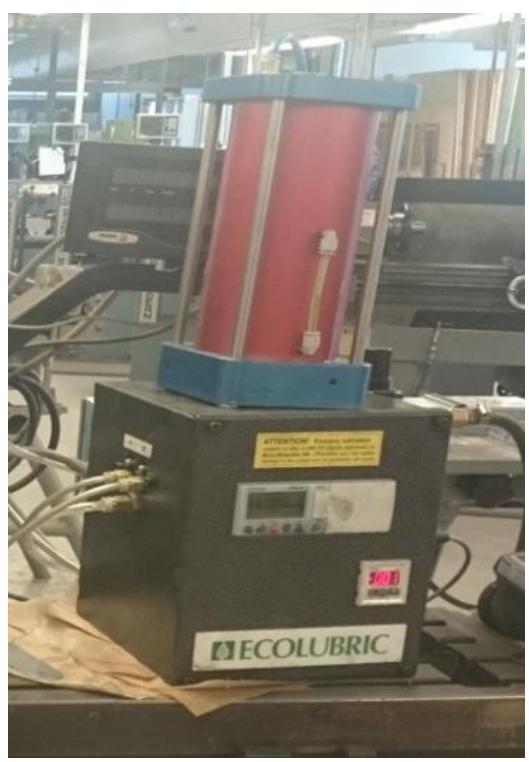

FIG. 3: MQL SYSTEM 
In this study, the tools are manufactured from A2 tool steel due to its resistance to thermal fatigue, cracking, and high toughness. The pin is a smooth trapezoidal cylinder, containing no threads, tapers, or other welding enhancement designs as shown in Figure (2).

To enhance the FSW process characteristics, the MQL process is applied in this study. Figure (3) explains the micro lubricating MQL system that is used with different variables. This system using a micro-pump which deliver too small amounts of oil. The vegetable oil that will be used is rapeseed oil, and ECOLUBRIC E200.

The specimens are machined from each welded plate subjected to tensile testing with geometry according to ASTM standards, using a dog bone shape in a sample of $32 \mathrm{~mm}$ gauge length. Tensile testing is applied to each weld at room temperature and perpendicular to the weld direction using an Instron-type tensile testing machine. Three samples are machined from each welded plate. For each sample prepared, ultimate tensile strength and efficiency are calculated, and the results are averaged.

\section{DATA ANALYSIS}

Table (6) shows the ANOVA test for the UTS of the welded metals. This analysis is conducted at a confidence interval of $95 \%$. As the P-value is zero for the spindle speed and the feed rate factors, they have significant effects on UTS results. As shown in the table, the lubricant factor is not independently significant. This might be because it has only two levels, while it is observed that the interaction of the lubricant factor with the spindle speed factor and feed rate factor has a significant effect. This reflects the importance of the types of the lubricant on the spindle speed and feed rate. Additionally, there is a significant effect of the triple interaction between the spindle speed, feed rate, and the lubricant.

\begin{tabular}{lccccc}
\multicolumn{5}{c}{ TABLE (6): ANOVA TEST RESULTS FOR TENSILE STRENGTH } \\
\hline Source & DF & Adj SS & AdjMS & F-value & P-Value \\
\hline Spindle Speed & 4 & 110916 & 27729 & 601.09 & 0 \\
Feed Rate & 2 & 9524 & 4762.1 & 103.23 & 0 \\
$\begin{array}{l}\text { Lubricant } \\
\text { Spindle }\end{array}$ & 1 & 18 & 17.7 & 0.38 & 0.537 \\
$\begin{array}{l}\text { Speed*Feed rate } \\
\text { Spindle }\end{array}$ & 8 & 7993 & 999.1 & 21.66 & 0 \\
$\begin{array}{l}\text { Speed*Lubricant } \\
\text { Feed }\end{array}$ & 4 & 3902 & 975.5 & 21.15 & 0 \\
$\begin{array}{l}\text { Rate* } \text { Lubricant } \\
\text { Spindle Speed }\end{array}$ & 2 & 2209 & 1104.4 & 23.94 & 0 \\
*Feed & & & & & \\
Rate* $*$ Lubricant & 8 & 4609 & 576.1 & 12.49 & 0 \\
Error & 90 & 4152 & 46.1 & & \\
Total & 119 & 143322 & & & \\
\hline
\end{tabular}

Note: DF: The total Degree of Freedom, Adj SS: Adjusted sums of squares, Adj MS: Adjusted mean squares.

Table (7) shows the Fisher pairwise comparisons of the effect of the spindle speed levels on UTS. The spindle speed with $1600 \mathrm{rpm}$ records the highest UTS, which significantly differs from 1900, 2200, and 1000 rpm respectively; while there is no significant difference between 1600 and $1300 \mathrm{rpm}$. Also, the levels of 1300 and $1900 \mathrm{rpm}$ are significantly different from 2200 and $1000 \mathrm{rpm}$. As tool spindle speed increases more than $1600 \mathrm{rpm}$, the resulting higher temperature cause to wider Heat Affected Zone, that leading to reduction in tensile strength at the jointed area. Also, the friction produces progressively more intensive stirring and mixing of the metal workpiece from lower to upper surface, thus decreasing the tensile strength. This means that any future study can rely on these levels for optimization or economic concept.

TABLE (7): FISHER TEST RESULTS FOR SPINDLE SPEED OF UTS

\begin{tabular}{cccc}
\hline Levels $($ rpm $)$ & $\boldsymbol{N}$ & Mean & Grouping \\
\hline $\mathbf{1 6 0 0}$ & 24 & 205.19 & $\mathrm{~A}$ \\
$\mathbf{1 3 0 0}$ & 24 & 196.85 & $\mathrm{AB}$ \\
$\mathbf{1 9 0 0}$ & 24 & 187.38 & $\mathrm{~B}$ \\
$\mathbf{2 2 0 0}$ & 24 & 160.34 & $\mathrm{C}$ \\
$\mathbf{1 0 0 0}$ & 24 & 121.46 & $\mathrm{D}$
\end{tabular}

The feed rate factor has recorded the highest effect on the UTS at $180 \mathrm{~mm} / \mathrm{min}$ as shown in Table (8), which presents the Fisher pairwise comparisons of the feed rate levels on UTS. As Fisher test of the feed rate factor, $180 \mathrm{~mm} / \mathrm{min}$ has a significant effect on the tensile strength. The heat generated is reduced when the feed rate becomes higher because the interaction time between the material and FSW tool is decreased; that the reduced heat generation might produce the formation of a tunnel defect inside the insufficient metal flow of the bottom region. Thus, when the feed rate is increased, correspondingly, the tensile strength properties also increase to a maximum at $180 \mathrm{~mm} / \mathrm{min}$.

TABLE (8): FISHER TEST RESULTS FOR FEED RATES OF UTS

\begin{tabular}{cccc}
\hline Levels $(\mathbf{m m} / \mathbf{m i n})$ & $\boldsymbol{N}$ & Mean & Grouping \\
\hline 180 & 40 & 186.60 & P-Yalue \\
100 & 40 & 170.18 & B \\
260 & 40 & 165.94 & B \\
& & & 0.537
\end{tabular}

IV. CONCLUSIONS: 0

This study investigated the effect of MQLOon the welding properties of AA 6061-T651. Statistical analysis is conducted to achieve the influence of controlled factors on the tensile strength. According to the ANOVA results, the following conclusions may be drawn: 0

1. The controlled parameters, spindle speed and the feed rate, have a significant effect on weld joint strength.

2. The interaction of lubricant factor has a significant effect with the spindle speed factor and feed rate factor, which means that the lubricant depends on the value of these factors.

3.The spindle speed with $1600 \mathrm{rpm}$ records the highest UTS, it might be because of finer grain size produced at this spindle speed. 
4. The feed rate factor has recorded the highest effect on the UTS at $180 \mathrm{~mm} / \mathrm{min}$.

\section{ACKNOWLEDGMENT}

The authors acknowledge the support of the Natural Sciences and Engineering Research Council of Canada (NSERC) and Ontario centers of Excellence (OCE). The first author acknowledges the Iraqi Ministry of Higher Education and Scientific research for their support of this research. References

[1] Ungureanu, Constantin Adrian. "Design for sustainability: product lifecycle analysis in aluminum auto body applications." (2007).

[2] Mathers, Gene. The welding of aluminium and its alloys. Woodhead publishing, 2002.
[3] Fratini, L., G. Buffa, and R. Shivpuri. "Influence of material characteristics on plastomechanics of the FSW process for Tjoints." Materials \& Design 30, no. 7 (2009): 2435-2445.

[4] Dialami, N., M. Chiumenti, M. Cervera, and C. Agelet De Saracibar. "Challenges in thermo-mechanical analysis of friction stir welding processes." Archives of Computational Methods in Engineering 24, no. 1 (2017): 189-225.

[5] Sharma, Anuj Kumar, Arun Kumar Tiwari, and Amit Rai Dixit. "Effects of Minimum Quantity Lubrication (MQL) in machining processes using conventional and nanofluid based cutting fluids: A comprehensive review." Journal of cleaner production127 (2016): 1-18.

[6] Davis, Joseph R. "Aluminum and aluminum alloys." (2013). 